\title{
The Range of Intrinsic Frequencies Represented by Medial Entorhinal Cortex Stellate Cells Extends with Age
}

\author{
Anne Boehlen, ${ }^{1,3}$ Uwe Heinemann, ${ }^{1,2,3}$ and Irina Erchova ${ }^{4}$ \\ ${ }^{1}$ Institute of Neurophysiology, Charité, and ${ }^{2}$ NeuroCure Research Center, 10117 Berlin, Germany, ${ }^{3}$ Bernstein Center for Computational Neuroscience Berlin, \\ 10115 Berlin, Germany, and ${ }^{4}$ Institute for Adaptive and Neural Computation, School of Informatics and Centre of Neuroscience Research, University of \\ Edinburgh, Edinburgh EH8 9AB, United Kingdom
}

In both humans and rodents, the external environment is encoded in the form of cognitive maps. Neurons in the medial entorhinal cortex $(\mathrm{mEC})$ represent spatial locations in a sequence of grid-like patterns scaled along the dorsal-ventral axis. The grid spacing correlates with the intrinsic resonance frequencies of stellate cells in layer II of mEC. We investigated the development of frequency preferences in these cells from weaning to adulthood using patch-clamp and sharp microelectrode recordings. We found that the dorsal-ventral gradient of stellate cell properties and frequency preferences exists before animals are able to actively explore their environment. In the transition to adulthood, cells respond faster and become less excitable, and the range of intrinsic resonance frequencies in the population expands in the dorsal direction. This is likely to reflect both the growth of the brain and the expansion of the internal representation caused by new exploratory experience.

\section{Introduction}

The neuronal correlates of the development of spatial representation of the external environment are not yet fully understood. The medial entorhinal cortex ( $\mathrm{mEC}$ ) has become the main focus of research into this topic after the discovery in rodents that a large proportion of cells in this area represent external space as an internal sequence of multiple triangular "grids" (Fyhn et al., 2004; Hafting et al., 2005). The resolution of a grid in relation to external space can vary from a few meters to tens of centimeters (Brun et al., 2008). The majority of grid cells are found in layer II of $\mathrm{mEC}$, and the size of the grid changes along the dorsoventral axis (Sargolini et al., 2006). Interestingly, the properties of the principal neurons in this area (often called stellate cells because of their distinctive shape) are defined by the composition of voltagedependent channels embedded in their membrane and change as a function of their position along the dorsoventral axis (Giocomo et al., 2007). The frequencies of both resonance and membrane potential oscillations depend on the position of the neuron along this axis (Giocomo et al., 2007) as does the expression pattern of HCN channels (Garden et al., 2008; Giocomo and Hasselmo, 2008a). This suggests that the spacing of the grid may be deter-

Received 0ct. 5, 2009; revised Feb. 4, 2010; accepted Feb. 7, 2010.

This work was supported by German Research Foundation (Deutsche Forschungsgemeinschaft) Grant He 1128/ 15-1, Bernstein Center for Computational Neurosciences Berlin from Bundesministerium für Bildung und Forschung and Graduiertenkolleg 1123 Cellular Mechanisms of Learning and Memory Consolidation in the Hippocampal Formation, Boehringer Ingelheim Fonds, Royal Society of Edinburgh/Lloyds TSB (personal fellowship to I.E.), and Engineering and Physical Sciences Research Council/Medical Research Council-funded Doctoral Training Centre in Neuroinformatics and Computational Neuroscience, University of Edinburgh. We thank D. Wyllie and M. Nolan (University of Edinburgh) for fruitful discussions and support.

Correspondence should be addressed to Dr. Irina Erchova, Institute for Adaptive and Neural Computation, School of Informatics, University of Edinburgh, Informatics Forum, 10 Crichton Street, Edinburgh EH8 9AB, UK. E-mail: ierchova@staffmail.ed.ac.uk.

DOI:10.1523/JNEUROSCI.4939-09.2010

Copyright $\odot 2010$ the authors $\quad 0270-6474 / 10 / 304585-05 \$ 15.00 / 0$ mined by the intrinsic properties of these cells (Hasselmo and Brandon, 2008).

The development of stellate cell excitability in the first postnatal weeks has been recently addressed by Burton et al. (2008). Here, we extend their study by investigating the development of the gradient in stellate cell properties from weaning [postnatal days 21-25 (P21-P25) to adulthood when rats most actively explore their environment (Whishaw and Kolb, 2004; McCutcheon and Marinelli, 2009). Throughout the study, we used both patch clamp and sharp microelectrode recordings to distinguish developmental changes from variability in the measurements introduced by different recording techniques.

\section{Materials and Methods}

Male Wistar rats were decapitated under halothane (in accordance with United Kingdom Home Office procedures) or ether anesthesia (Berlin Animal Ethics Committee; T 0068/02), and horizontal slices (400 $\mu \mathrm{m})$ containing the hippocampus and the perirhinal and entorhinal cortex were prepared as previously reported (Erchova et al., 2004). After gluing the cortical surface to the mount, slices were cut from ventral to dorsal towards the bregma. The slice position was measured in relation to the interaural line (Paxinos and Watson, 1998). Slices were incubated in the recording solution for at least $1 \mathrm{~h}$ before being transferred to a submerged (patch clamp) or an interface humidified (sharp microelectrode) recording chamber at $34 \pm 1^{\circ} \mathrm{C}$. Excitatory and inhibitory synaptic transmission was blocked. In a subset of experiments, the identity of recorded cells was confirmed histologically as previously reported from our laboratory (Gloveli et al., 1997; Erchova et al., 2004). The topographical location of recorded cells was taken as the position of the slice plus one-half of slice thickness. Recorded cells were sorted into two groups (ventral, 2.0-4.0 $\mathrm{mm}$; dorsal, 4.1-6.2 mm).

The recordings were done using either patch clamp or sharp microelectrodes (see supplemental material, available at www.jneurosci.org) in current-clamp mode, bridge balance adjusted. Patch pipettes (5-6 M $\Omega$ ) were filled with an intracellular solution (in mM: $140 \mathrm{~K}$-gluconate, 2 
$\mathrm{MgCl}_{2}, 10$ phosphocreatine, $2 \mathrm{Na}_{2} \mathrm{ATP}, 0.4 \mathrm{NaGTP}, 10 \mathrm{HEPES}$, and $0.4 \%$ biocytin, pH 7.3). Recordings were obtained using a Multiclamp 700B amplifier, filtered at $3 \mathrm{kHz}$, digitized at $10-100 \mathrm{kHz}$, and acquired using Clampex 9.0 (Molecular Devices).

Data analyses were performed using Clampfit 9.0 (Molecular Devices) and custom software written in Matlab (version 7.4; Mathworks). Input resistance, membrane time constant, rheobase, sag potential, and action potential (AP) parameters including analysis of afterpotentials (see supplemental material, available at www.jneurosci.org) were estimated from the response of the cell to a square current pulse of $500 \mathrm{~ms}$. The time course for the sag potential (SAG-Tau) was analyzed from the voltage response to $-400 \mathrm{pA}$ using a double-exponential function (Giocomo et al., 2007) (see supplemental Fig. S1 A, available at www.jneurosci.org as supplemental material). The AP parameters were estimated from the first spike elicited by the rheobase stimulus (for details, see supplemental Fig. $\mathrm{S} 1 \mathrm{~B}$, available at www.jneurosci.org as supplemental material). The resonance frequency of a cell was determined from the average voltage response (five repetitions) to a sinusoidal current injection with linearly increasing frequency from 0 to $20 \mathrm{~Hz}$ over $30 \mathrm{~s}$ (Puil et al., 1986; Hutcheon and Yarom, 2000; Erchova et al., 2004). The measurements were obtained at three levels of membrane potential (hyperpolarized, approximately $-75 \mathrm{mV}$; resting; depolarized, approximately $-52 \mathrm{mV}$ ). The amplitude of oscillating command current was adjusted to avoid changes in the membrane potential by $>10 \mathrm{mV}$. The input frequency corresponding to the highest impedance was defined as the resonance frequency. The amplitude ( $Q$ value) of the resonance was determined as the ratio of the peak impedance to the impedance at zero frequency. The dominant frequency of membrane potential oscillations (MPOs) (evoked by depolarization to near threshold by injecting a constant current $10 \mathrm{pA}$ smaller than the rheobase) was determined from the power spectra analysis (Erchova et al., 2004) as the frequency between 1 and 15 $\mathrm{Hz}$ with the highest power. MPOs were analyzed near spiking threshold on at least 2-s-long data subsets without spikes. All values are reported as mean \pm SEM. For multiple comparisons, the multivariant ANOVA and two-tailed Student's $t$ test was used (Origin 6.0; OriginLab). Regression lines and fits of distributions were constructed using the Matlab Statistic Toolbox. The test results are abbreviated as follows: ${ }^{\star} p<0.05 ;{ }^{*} p<$ $0.01 ;{ }^{* \star *} p<0.001$; or n.s., not significant.

\section{Results}

We examined changes in excitability of mEC stellate cells from weaning to adulthood using both patch-clamp (juvenile: P20.8 \pm 0.4, P17-P25, 48 cells; adult: P46.4 \pm 0.7, P34-P56, 79 cells) and sharp microelectrode recordings (juvenile: P18.0 \pm 0.5, P14-P22, 28 cells; adult: P93 \pm 3 , P73-P110, 58 cells). The patch-clamp results are presented in the main text, whereas most of the sharp microelectrode results and the overall summary table are in the supplemental material (available at www.jneurosci.org).

In juvenile rats, we found that cellular excitability changed as a function of cell position. The input resistance and time constant increased from dorsal to ventral, whereas the rheobase decreased (Fig. $1 B-D$; supplemental Fig. S2 A, B, available at www.jneurosci.org as supplemental material). No difference in resting membrane potential or voltage threshold for AP initiation was observed. The ventral cells were more excitable and needed less current to elicit a spike, but at rheobase the dorsal cells produced a spike earlier ( $91 \pm 24$ vs $144 \pm 21 \mathrm{~ms}$ ) (Fig. $1 A)$. In adults, the rheobase increased $(p<0.001)$, reflecting a decrease in cellular excitability. We attributed these changes to the reduced input resistance $(p<0.001)$. It was, however, also accompanied by a decrease in the AP voltage threshold (from $-50 \pm 1$ to $-53 \pm 1 \mathrm{mV}$ ). In addition, all cells responded faster to current injections as indicated by their decreased membrane time constants $(p<0.001)$. We evaluated the contribution of HCN channels by estimating the fast time constant for their activation from the sag potential (Giocomo et al., 2007) (supplemental Fig. S1 B, available at www.jneurosci.org as supplemental material). The SAG-Tau was reduced for dorsal cells $(p<0.001)$ and decreased in adults $(p<0.01)$ (Fig. $1 E$; supplemental Fig. S2C, available at www.jneurosci.org as supplemental material). In addition, we measured a number of AP parameters including afterhyperpolarization (AHP) (supplemental Fig. S1B, available at www. jneurosci.org as supplemental material). In juvenile rats, none of the AHP components [fast AHP (fAHP), depolarizing afterpotential, medium AHP (mAHP) amplitude and duration] showed any significant correlation with cell position. However, the halfwidth of AP increased from dorsal to ventral cells (slope, -0.06 ; $r=-0.53 ; p<0.001)$. In adults, the fAHP decreased from $7-8$ to 4-5 $\mathrm{mV}$, the gradient in AP half-width duration became steeper (slope, $-0.1 ; r=-0.56 ; p<0.001$ ), and the duration of $\mathrm{mAHP}$ also became correlated with the cell position (Fig. $1 F$ ) (for details, see supplemental Methods and Fig. S2D, available at www. jneurosci.org as supplemental material).

We characterized the frequency preferences of cells by measuring the membrane resonance and MPOs. The resonance frequency decreased along the dorsal-ventral axis in both juvenile and adult rats $(p<0.001)$, but the range of frequencies in adults was larger than in juvenile rats (Fig. 2; supplemental Fig. S3, available at www.jneurosci.org as supplemental material). Interestingly, during the transition to adulthood, the most distant ventral cells remained virtually unchanged, whereas the dorsal cells changed their frequency almost twofold $(p<0.001)$. We found that, in adults but not juvenile rats, the mAHP duration was correlated with the resonance frequency at both resting membrane potential and just below threshold $\left(r_{\text {rest }}=0.56, p<\right.$ $\left.0.001 ; r_{\text {dep }}=0.42, p<0.01\right)$. In general, the resonance frequency decreased with depolarization $(p<0.001)$ (Fig. $2 C$ ) and input resistance increased $(p<0.001)$. The MPO frequency also decreased from dorsal to ventral cells $(p<0.001)$ (Fig. 3) similar to the resonance frequencies but with slightly lower values. The MPOs obtained in patch-clamp recordings had, however, lower frequencies (Fig. $3 A, B$ ) compared with sharp microelectrode recordings (Fig. $3 C, D$ ) and did not show any age dependency.

\section{Discussion}

Our results suggest that the dorsal-ventral gradient of stellate cell properties develops before the age of active exploration and is likely to be genetically determined. During the transition to adulthood, cells become less excitable and the frequency preferences of individual cells change differentially in such a way that the range of frequencies represented by the population expands in the dorsal direction.

Although it is known that the age can be a critical source of variability in the data, the age-related differences can be confounded because of the use of different recording techniques in different age groups. To clarify this issue, we performed both patch-clamp and sharp microelectrode recordings. Although our main findings were consistent across both techniques, the membrane time constants of cells measured using sharp microelectrodes were smaller because of lower input resistance. Consequently, the range of resonance frequencies recorded by sharp microelectrodes was larger (the cutoff frequency of the cell low-pass filter depends on $\left.1 / 2 \pi \tau_{\mathrm{m}}\right)$. In both age groups, the resonance frequency decreased on depolarization similar as reported by Nolan et al. (2007), although the effect was weak when measured by sharp microelectrodes, similar to the study by Erchova et al. (2004). In all cases, the resonance frequency measured near threshold was larger than the frequency of MPOs, as we previously reported (Erchova et al., 2004; Engel et al., 2008). However, 
A
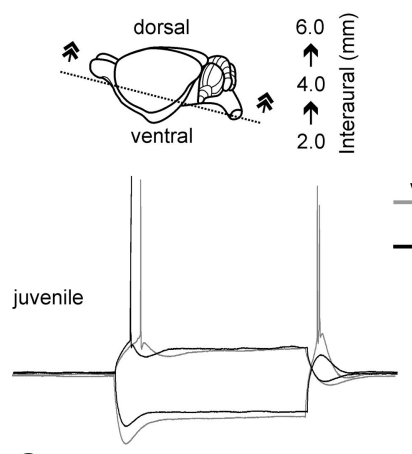

C

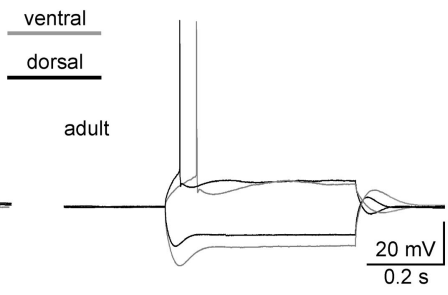

juvenile: slope $=-3.60 ; r=-0.73$

adult: slope $=-3.27 ; r=-0.71$

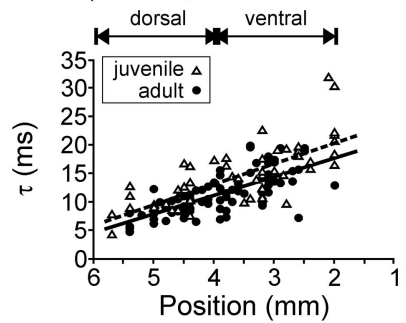

$\mathrm{E}$

juvenile: slope $=-3.76 ; r=-0.39$

adult: slope $=-3.83 ; r=-0.44$
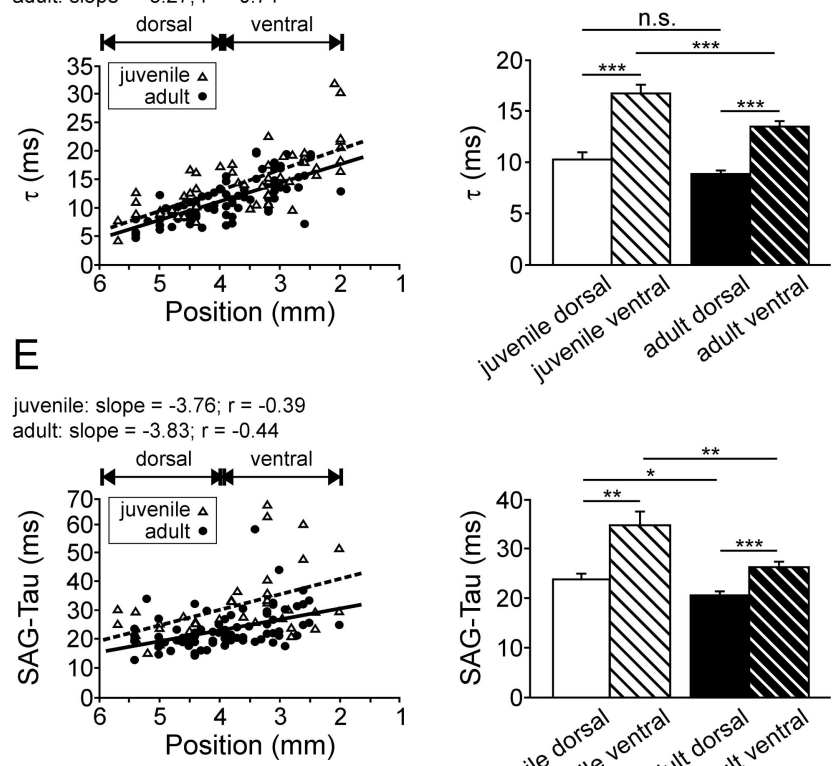

B

juvenile: slope $=-21.22 ; r=-0.69$

adult: slope $=-13.21 ; r=-0.56$

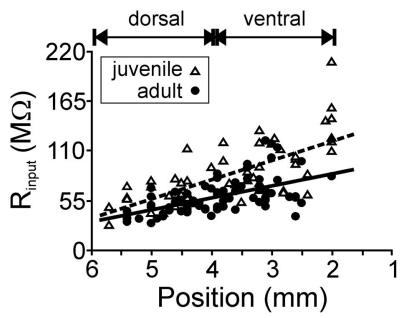

D

juvenile: slope $=45.93 ; r=0.71$

adult: slope $=58.19 ; r=0.55$

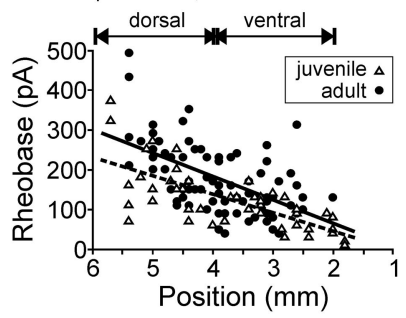

$\mathrm{F}$

juvenile: slope $=-1.26 ; r=-0.06$

adult: slope $=-19.55 ; r=-0.48$

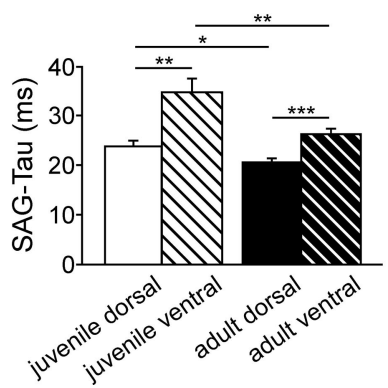

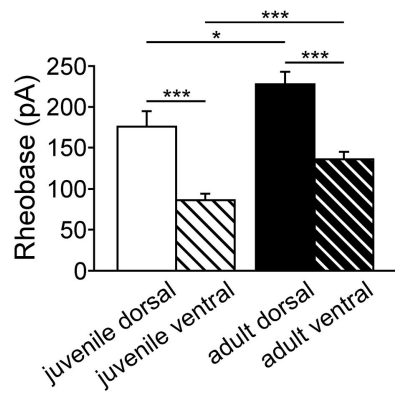
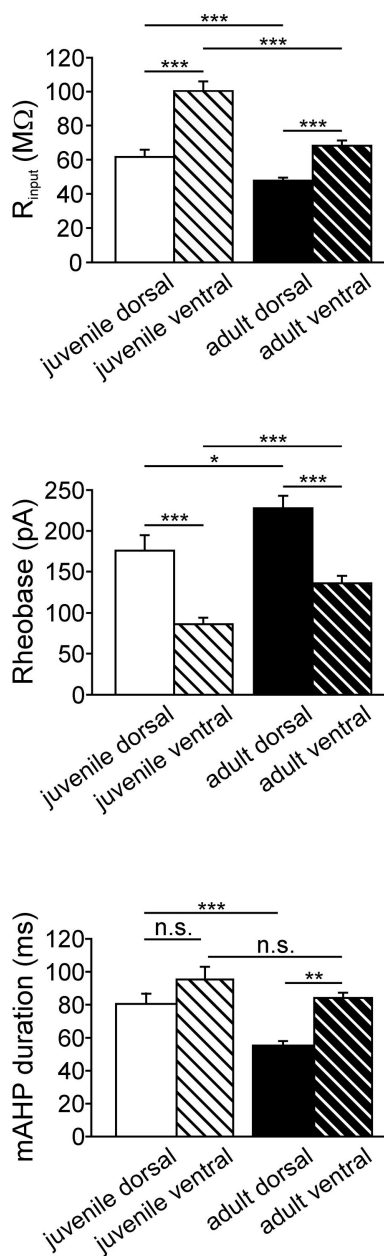

Figure 1. The stellate cell properties in juvenile and adult rats vary along the dorsoventral axis of the $\mathrm{mEC}$. $\boldsymbol{A}, \mathrm{A}$ diagram of brain slicing and typical responses of ventral and dorsal cells to a current pulse of $-400 \mathrm{pA}$ and to a rheobase pulse. $\boldsymbol{B}-\boldsymbol{F}$, Input resistance $(\boldsymbol{B})$, membrane time constant $(\boldsymbol{C})$, rheobase $(\boldsymbol{D})$, SAG-Tau $(\boldsymbol{E})$, and mAHP duration $(\boldsymbol{F})$ plotted as a function of cell position and rat age (left) and as mean values for dorsal and ventral cells (right). In all panels, the dashed line represents a linear regression for juvenile cells, and the solid line represents a linear regression for adult cells; $r$ is the correlation coefficient. All data were obtained using patch-clamp recordings. Error bars indicate SEM. ${ }^{*} p<0.05 ;{ }^{* *} p<0.01 ;{ }^{* * *} p<0.001 ;$ n.S., not significant.

the smaller range of measured frequencies in patch-clamp data, combined with prominent voltage-dependent decrease in resonance frequency, resulted in remarkable differences between MPOs data recorded by patch clamp and sharp microelectrode.

In our study, near-threshold MPOs showed no consistent significant voltage-dependent variations in frequency. However, the original study by Alonso and Llinás (1989) reported an increase in MPO frequencies on depolarization. This was recently confirmed by Giocomo and Hasselmo (2008b), who also specified that this effect was mainly seen in dorsal, but not ventral cells. Previously, we observed a similar increase in a subset of cells when both subthreshold and perithreshold MPOs were considered (Erchova et al., 2004).

It is well accepted that the establishment of receptive fields and refinement of synaptic circuitry depends on sensory experience (Moody and Bosma, 2005). However, changes in synaptic strength might be accompanied by changes in intrinsic excitability as a means to maintain stability in neuronal circuits (for review, see Desai, 2003; Nelson and Turrigiano, 2008; Yu and Goda, 2009). To this end, the maturation of synapses would require faster cellular responses and an overall reduction in cell excitability, as we observed. The situation is more complex when intrinsic excitability is differentially regulated across the cellular population (for review, see Sjöström et al., 2008), adjusting its sensitivity to the temporal aspects of the input pattern. It is usually difficult to dissociate the effects of sensory experience and genetically prescribed patterns of postnatal maturation. Burton et al. (2008) found that dendritic spine density of mEC layer II stellate cells increased almost threefold from the second to the fourth postnatal week without changes of stellate cell excitability beyond P18. However, as our data show, the intrinsic excitability continues to change differentially within the population.

In stellate cells, frequency preferences are defined mainly by HCN and potassium channels (White et al., 1995; Fransén et al., 2004; Schreiber et al., 2004). It is therefore interesting that Burton et al. (2008) found a continuous increase in the expression of HCN channels up to the end of their study at P28, although they did not find a clear physiological correlate of this process. This pattern agrees with data by Richter et al. (1997) and with our own findings showing age-related acceleration of the sag potential. It 
A

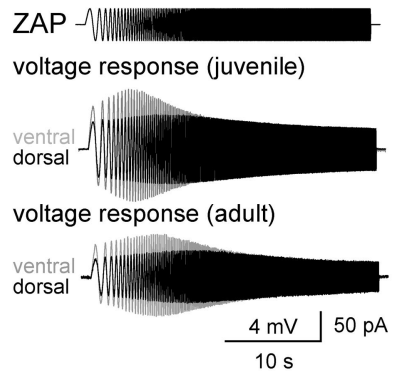

B

juvenile: slope $=0.88 ; r=0.74$
adult: slope $=1.81 ; r=0.78$

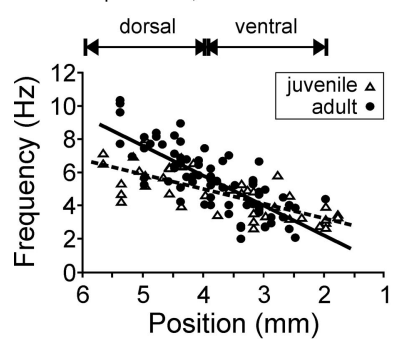

C

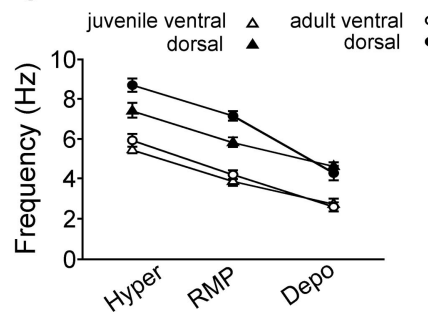

A
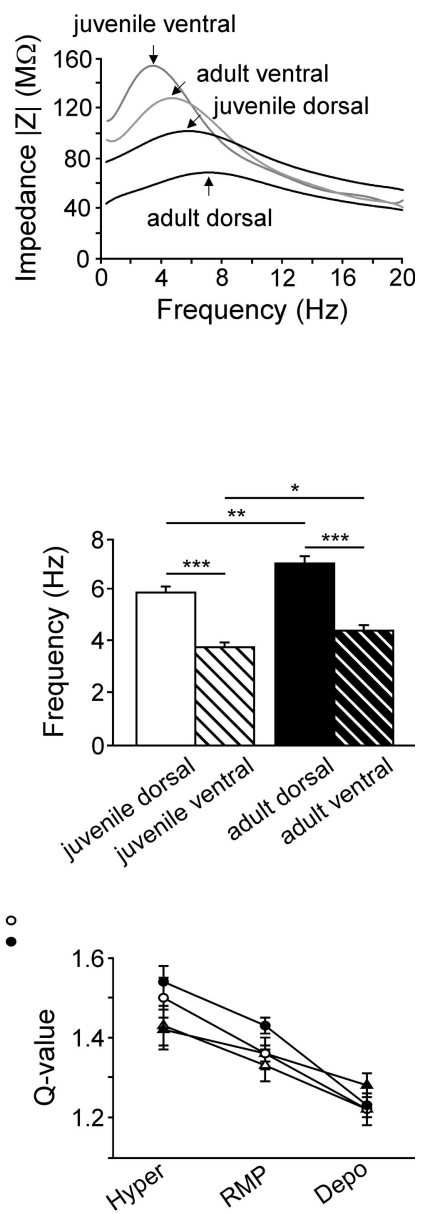

Figure 2. The range of frequencies represented by stellate cells expands with age. $A$, Typical responses of dorsal and ventral cells to a ZAP current $0-20 \mathrm{~Hz}$ (left) and membrane resonance profiles (right). $\boldsymbol{B}$, Resonance frequency plotted as a function of cell position and rat age (left) and as mean values for dorsal and ventral cells (right). $\boldsymbol{C}$, Resonance frequency (left) and amplitude $Q=Z_{\text {Res }} / Z_{0}$ (right) plotted as a function of membrane potential at hyperpolarized (approximately $-75 \mathrm{mV}$ ), resting, and depolarized (approximately $-52 \mathrm{mV}$ ) levels. All data were obtained using patch-clamp recordings. Error bars indicate SEM. ${ }^{*} p<0.05$; ${ }^{* *} p<0.01$; ${ }^{* * *} p<0.001$.

is not yet clear whether this is caused by a systematic variation in activation kinetics [as suggested by Giocomo and Hasselmo (2008a)] or by a pure difference in the number of HCN channels. In the rat hippocampus, for example, the HCN current both increases and accelerates because of the substitution of the slow HCN4 by the fast HCN1 isoform (Surges et al., 2006). It is interesting, then, that in HCN1-deficient mice the observed gradient in stellate cells properties flattens (Giocomo and Hasselmo, 2009), suggesting that regulation of this subunit might be essential.

At present, little is known about how potassium currents shape resonance in stellate cells; we found that both AP halfwidth and mAHP duration were positively correlated with resonance frequency in adults, although only AP width correlated with resonance frequency in juvenile cells. This suggests that some of the currents shaping mAHP and spike-activated currents might also contribute to the increase in resonance frequency.

Many cortical areas increase considerably in size during postnatal development, but it is not clear how this impacts the remod-

\section{patch clamp recordings}

juvenile

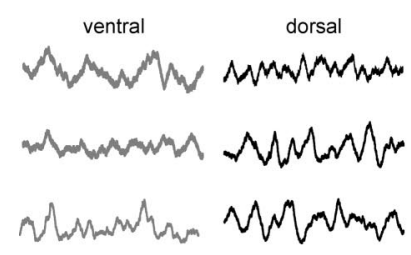

adult

Nentral Nan Nommars

Morman NWWWW

WNAWW MWMWM

$\frac{1}{0.5 \mathrm{~s}} \mathrm{mV}$

B
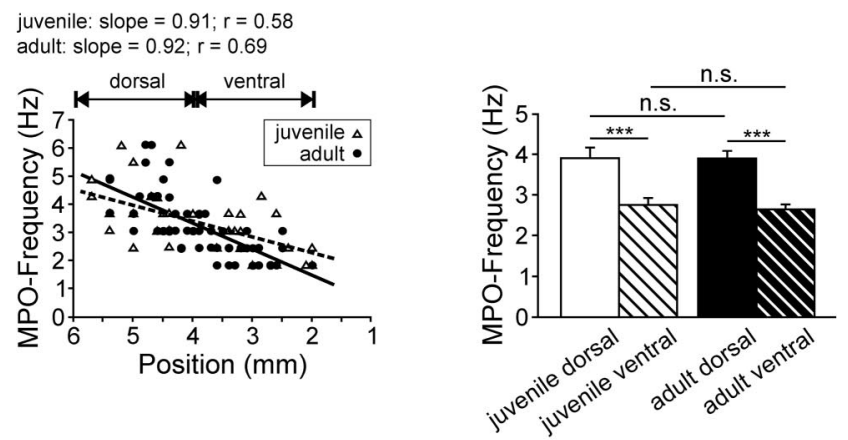

\section{C sharp microelectrode recordings}

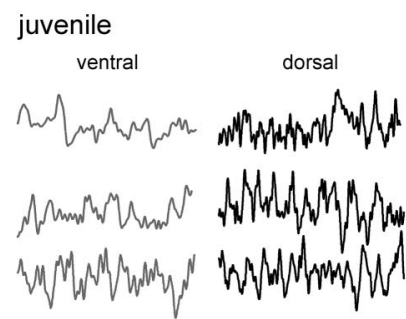

D

juvenile: slope $=1.61 ; r=0.73$

adult: slope $=1.76 ; r=0.66$

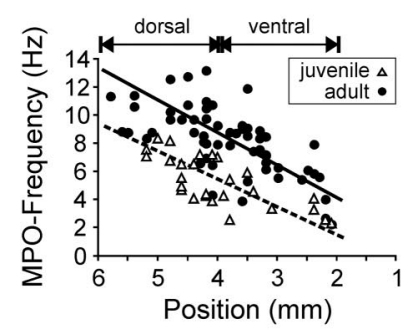

adult
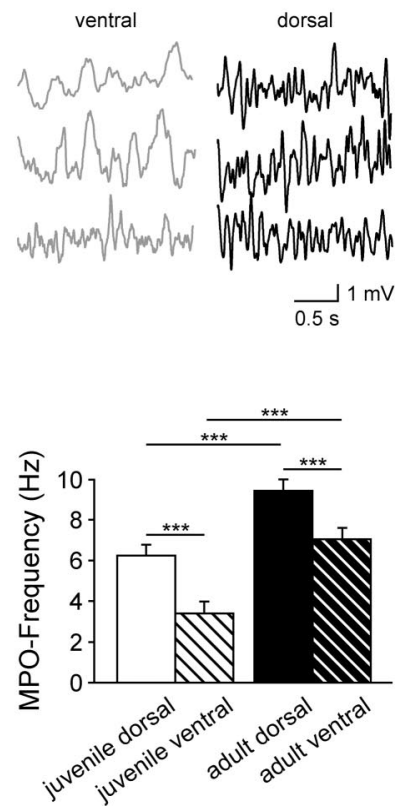

Figure 3. MPOs frequencies vary with cell position. $A$, Examples of MPOs for dorsal and ventral cells as recorded by patch clamp. $\boldsymbol{B}, \mathrm{MPO}$ frequency (patch clamp) plotted as a function of cell position and rat age (left) and as mean values for dorsal and ventral cells (right). C, Examples of MPOs for dorsal and ventral cells as recorded by sharp microelectrode. D, MPO frequency (sharp microelectrode) plotted as a function of cell position and rat age as mentioned before. Error bars indicate SEM. ${ }^{* * *} p<0.001 ;$ n.S., not significant.

eling of neuronal circuits. One intriguing possibility suggested by our study is that the range of frequencies represented by stellate cells might extend without necessarily affecting the frequency preferences of already established cells. The anatomy of EC favors extension in the dorsal direction (Steffenach et al., 2005), because ventral mEC contains several lateral bands, with only one band 
associated with the representation of space, whereas the dorsal $\mathrm{mEC}$ is homogeneous in its spatial function (Dolorfo and Amaral, 1998; Kerr et al., 2007).

Although it is not yet precisely known how the population of grid cells encodes a location, the oscillatory interference model (Burgess et al., 2007) would predict that receptive fields of dorsal cells in young animals would have slightly larger grids compared with adults, given that synaptic connections are formed and receptive fields are established. However, in the modular code suggested by Fiete et al. (2008) in which an animal's position is encoded by the population with a large number of unique spatial frequencies, the total number of represented locations grows exponentially with the number of spatial frequencies available. Accordingly, an extension of the range of frequencies might reflect both an expansion of internal space representation in accordance with new exploratory experiences and refinement of existing representations.

To conclude, our data suggest that intrinsic mechanisms allow for the rapid formation of a cognitive spatial map that can readily rescale during development, preserving already acquired representations, increasing the spatial resolution of the map, and allowing for the encoding of novel locations.

\section{References}

Alonso A, Llinás RR (1989) Subthreshold $\mathrm{Na}^{+}$-dependent theta-like rhythmicity in stellate cells of entorhinal cortex layer II. Nature 342:175-177.

Brun VH, Solstad T, Kjelstrup KB, Fyhn M, Witter MP, Moser EI, Moser MB (2008) Progressive increase in grid scale from dorsal to ventral medial entorhinal cortex. Hippocampus 18:1200-1212.

Burgess N, Barry C, O’Keefe J (2007) An oscillatory interference model of grid cell firing. Hippocampus 17:801-812.

Burton BG, Economo MN, Lee GJ, White JA (2008) Development of theta rhythmicity in entorhinal stellate cells of the juvenile rat. J Neurophysiol 100:3144-3157.

Desai NS (2003) Homeostatic plasticity in the CNS: synaptic and intrinsic forms. J Physiol Paris 97:391-402.

Dolorfo CL, Amaral DG (1998) Entorhinal cortex of the rat: topographic organization of the cells of origin of the perforant path projection to the dentate gyrus. J Comp Neurol 398:25-48.

Engel TA, Schimansky-Geier L, Herz AV, Schreiber S, Erchova I (2008) Subthreshold membrane-potential resonances shape spike-train patterns in the entorhinal cortex. J Neurophysiol 100:576-589.

Erchova I, Kreck G, Heinemann U, Herz AV (2004) Dynamics of rat entorhinal cortex layer II and III cells: characteristics of membrane potential resonance at rest predict oscillation properties near threshold. J Physiol 560:89-110.

Fiete IR, Burak Y, Brookings T (2008) What grid cells convey about rat location. J Neurosci 28:6858-6871.

Fransén E, Alonso AA, Dickson CT, Magistretti J, Hasselmo ME (2004) Ionic mechanisms in the generation of subthreshold oscillations and action potential clustering in entorhinal layer II stellate neurons. Hippocampus 14:368-384.

Fyhn M, Molden S, Witter MP, Moser EI, Moser MB (2004) Spatial representation in the entorhinal cortex. Science 305:1258-1264.

Garden DL, Dodson PD, O’Donnell C, White MD, Nolan MF (2008) Tuning of synaptic integration in the medial entorhinal cortex to the organization of grid cell firing fields. Neuron 60:875-889.

Giocomo LM, Hasselmo ME (2008a) Time constant of $I_{\mathrm{h}}$ differs along dorsal to ventral axis of medial entorhinal cortex. J Neurosci 28:9414-9425.
Giocomo LM, Hasselmo ME (2008b) Computation by oscillations: implications of experimental data for theoretical models of grid cells. Hippocampus 18:1186-1199.

Giocomo LM, Hasselmo ME (2009) Knock-out of HCN1 subunit flattens dorsal-ventral frequency gradient of medial entorhinal neurons in adult mice. J Neurosci 29:7625-7630.

Giocomo LM, Zilli EA, Fransén E, Hasselmo ME (2007) Temporal frequency of subthreshold oscillations scales with entorhinal grid cell field spacing. Science 315:1719-1722.

Gloveli T, Schmitz D, Empson RM, Dugladze T, Heinemann U (1997) Morphological and electrophysiological characterization of layer III cells of the medial entorhinal cortex of the rat. Neuroscience 77:629-648.

Hafting T, Fyhn M, Molden S, Moser MB, Moser EI (2005) Microstructure of a spatial map in the entorhinal cortex. Nature 436:801-806.

Hasselmo ME, Brandon MP (2008) Linking cellular mechanisms to behaviour: entorhinal persistent spiking and membrane potential oscillations may underlie path integration, grid cell firing and episodic memory. Neural Plast 2008:658323.

Hutcheon B, Yarom Y (2000) Resonance, oscillation and the intrinsic frequency preferences of neurons. Trends Neurosci 23:216-222.

Kerr KM, Agster KL, Furtak SC, Burwell RD (2007) Functional neuroanatomy of the parahippocampal region: the lateral and medial entorhinal areas. Hippocampus 17:697-708.

McCutcheon JE, Marinelli M (2009) Age matters. Eur J Neurosci 29:9951014.

Moody WJ, Bosma MM (2005) Ion channel development, spontaneous activity, and activity-dependent development in nerve and muscle cells Physiol Rev 85:883-941.

Nelson SB, Turrigiano GG (2008) Strength through diversity. Neuron 60:477-482.

Nolan MF, Dudman JT, Dodson PD, Santoro B (2007) HCN1 channels control resting and active integrative properties of stellate cells from layer II of the entorhinal cortex. J Neurosci 27:12440-12451.

Paxinos G, Watson C (1998) The rat brain in stereotaxic coordinates. London: Academic.

Puil E, Gimbarzevsky B, Miura RM (1986) Quantification of membrane properties of trigeminal root ganglion neurons in guinea pigs. J Neurophysiol 55:995-1016.

Richter H, Klee R, Heinemann U, Eder C (1997) Developmental changes of inward rectifier currents in neurons of the rat entorhinal cortex. Neurosci Lett 228:139-141.

Sargolini F, Fyhn M, Hafting T, McNaughton BL, Witter MP, Moser MB, Moser EI (2006) Conjunctive representation of position, direction, and velocity in entorhinal cortex. Science 312:758-762.

Schreiber S, Erchova I, Heinemann U, Herz AV (2004) Subthreshold resonance explains the frequency-dependent integration of periodic as well as random stimuli in the entorhinal cortex. J Neurophysiol 92:408-415.

Sjöström PJ, Rancz EA, Roth A, Häusser M (2008) Dendritic excitability and synaptic plasticity. Physiol Rev 88:769-840.

Steffenach HA, Witter M, Moser MB, Moser EI (2005) Spatial memory in the rat requires the dorsolateral band of the entorhinal cortex. Neuron 45:301-313.

Surges R, Brewster AL, Bender RA, Beck H, Feuerstein TJ, Baram TZ (2006) Regulated expression of HCN channels and cAMP levels shape the properties of the h current in developing rat hippocampus. Eur J Neurosci 24:94-104.

Whishaw IQ, Kolb B (2004) The behavior of the laboratory rat: a handbook with tests. Oxford: Oxford Scholarship Online.

White JA, Budde T, Kay AR (1995) A bifurcation analysis of neuronal subthreshold oscillations. Biophys J 69:1203-1217.

Yu LM, Goda Y (2009) Dendritic signalling and homeostatic adaptation. Curr Opin Neurobiol 19:327-335. 